Boise State University

ScholarWorks

Nursing Faculty Publications and Presentations

School of Nursing

$11-1-2006$

\title{
Enhancing Evidence-Based Practice Through Collaboration
}

Pamela Springer

Boise State University

Carolyn Corbett

St. Alphonsus Regional Medical Center

Noreen Davis

St. Lukes Regional Medical Center 


\section{Enhancing Evidence-Based Practice Through Collaboration}

Pamela J. Springer, PhD, RN, Carolyn Corbett, MSN(R), MBA, RN, Noreen Davis, MBA, $\mathrm{MPH}, \mathrm{RN}$

Authors' Affiliations: Professor and Department Chair (Dr. Springer), Boise State University, Boise, ID; Vice President, Patient Care Services (Ms. Corbett), St. Alphonsus Regional Medical Center, Boise, ID; Senior Vice President, Nursing and Patient Care Services (Ms. Davis), St. Lukes Regional Medical Center, Boise, ID.

Corresponding Author: Pamela J. Springer, PhD, RN, Professor and Department Chair, Boise State University, 1910 University Drive, Boise, ID, 83725 (pspring@boisestate.edu). 


\begin{abstract}
Hospitals increasingly reference published evidence for any given procedure or guideline as part of the push towards evidence-based nursing. Medical centers and universities can develop a collaborative model to help support evidence-based practice. The authors describe a model of collaboration between a university and medical centers to enhance nurses’ knowledge and research skills and provide research opportunities for faculty.
\end{abstract}


Evidence-based practice has become the gold standard for nursing practice. Hospital nursing policy and procedure manuals increasingly reference the published evidence for any given procedure or guideline. The American Nurses Association’s Magnet Hospital designation process assesses the hospital's nursing care quality and the extent to which care is based on published evidence. "Evidence-based nursing is the process by which nurses make clinical decisions using the best available research evidence, their clinical expertise, and patient preferences. Three areas of research competence include: interpreting and using research, evaluating practice, and conducting research” (1).

Sorting through the research evidence requires some basic competence with research, including: (1) clearly identifying the issue or problem, (2) searching the literature for relevant research, (3) evaluating the research using established criteria, and (4) acting on the best available evidence (2). Nurse managers and nurse educators are each confronted with the need to help nurses better understand, critique, and use the research findings.

Many nurses practicing at the bedside are not prepared with the skills needed to base their practice on evidence. A large proportion of nurses in practice are prepared at the Associate degree or diploma level and have never had a research course. Even with baccalaureate preparation, nurses are not expert in analyzing the rigor of nursing research studies. Nursing leadership must develop programs to increase both awareness and competency in evaluating published research. 
This is a non-final version of an article published in final form in Journal of Nursing Administration, 36(11), 534-537. http://journals.lww.com/ jonajournal/pages/default.aspx

Nursing practice is demanding and fast paced. Practicing nurses do not have time in their practice day to conduct literature reviews to ensure each of their nursing interventions are evidence-based. Managers are challenged to develop systems that support evidence-based practice on their unit or across units in the facility. Strategies may include the use of nurse educators and/or clinical specialists on units and committees to help ensure policies and practices are evidence-based. Another strategy is the development of a collaborative model between a medical center and a local university.

Collaboration has been described as a relationship where the collaborators are actively involved with each other as they carry out their tasks (3). In a collaborative model, all parties recognize and value their mutual interdependency. Friend and Cook (3) identified six characteristics of collaboration. These include: (1) voluntary participation, (2) mutual valuing, (3) mutual goals, (4) shared responsibility, (5) shared resources, and (6) shared accountability.

Boise State University in Boise, Idaho, is currently engaged in collaborative joint research appointments with local medical centers. These medical centers include non-profit facilities with over 300 beds and smaller facilities both for and not-for profit with less than 100 beds. Each joint appointment is specific to the needs of the facility and focuses on enhancing quality patient care via many routes. These joint appointments serve to enhance the individual nurses knowledge and research skills, increase the rigor of policies, increase the faculty knowledge of the complexities of health care through lived experiences, and provide research opportunities for faculty and interested nursing staff. 
Joint appointments between a clinical practice and an academic institution have been in place for many years. A joint appointment is a formalized appointment between two institutions for an individual to carry out defined responsibilities in each institution (4). Joint appointments can take many forms. They may be focused on clinical practice, sharing of staff to teach, and/or research. Joint appointments are only limited by the creativity of the leadership in both the clinical and academic unit.

The academic nursing department has long enjoyed good working relationships with its clinical facilities. These relationships however consisted primarily of placing students in clinical facilities and encouraging faculty and staff to be on committees in each other's agencies. In the past, Boise State University was experiencing an increased push to enhance the research intensiveness of the institution. This influenced the nursing department to focus more of faculty time on scholarly endeavors. Concurrent with this push, the nursing profession has focused on the need to base all practice on evidence, while many facilities are seeking to reach Magnet Hospital status. These factors converged and allowed for fertile ground on which to discuss ways to expand relationships with our clinical facilities.

\section{Voluntary Participation}

The beginning of this new relationship consisted of an e-mail "floating” an idea. The nursing department chairperson sent an e-mail to local medical center administrators, asking, "What would it look like if we partnered in a different way? Would you be interested in discussing how we could place a doctoral-level faculty member in your facility for a few hours each week? The faculty could act as a research resource to the staff, promote evidence-based practice, and 
support the faculty's research agenda. What do you think?” This e-mail was met with responses that ranged from "We could never afford to do that" to "Yes, I am having my secretary call and set up a meeting right away.”

\section{Mutual Valuing}

A literature review was performed to provide information on joint appointment possibilities and some guidance on contractual issues and articles were shared. Separate meetings were initiated with two medical centers that expressed the most immediate interest. At these meetings, information was shared about needs, wants, and desires. The meetings were used to brainstorm what both partners hoped to gain from a joint appointment arrangement.

The negotiations to make the first joint appointment possible took almost eight months, and meetings occurred frequently. Initially, the meetings were between the nursing department chair and the vice president for nursing services to ensure the idea was attractive to both institutions. Meetings then branched out to include nurse educators, clinical specialists, and unit managers in the clinical agencies and interested faculty on the academic side. As the meetings involved more people, the focus shifted to specifics on what each institution brought to the relationship, what each institution wanted out of the relationship, and finally to the details of setting up and following through. After eight months of continued dialogue, a joint appointment agreement with one medical center was signed and a doctoral-level faculty member was placed the next fall. This was followed by another joint appointment the second fall. The third and fourth appointments are now in place during third and fourth years. 
This is a non-final version of an article published in final form in Journal of Nursing Administration, 36(11), 534-537. http://journals.lww.com/

Details of the contract signed by both parties in this joint venture included the following:

- Placement of a doctoral-level faculty in the facility for $20 \%$ of their contract to support research activities and evidence-based practice;

- The university provides statistical support for the professor and funding to present research findings at one conference per year;

- The university agrees to provide student research assistants and supplies, as appropriate, to meet the needs of a research project;

- The professor agrees to abide by the policies and practices of the medical center and the requirements for research;

- Requirements for research in the regional medical center are governed by the Institutional Review Boards of the medical center and the university;

- The medical center agrees to provide office space for the professor and access to staff and patients as needed for approved research projects;

- The medical center agrees to provide assistance from nursing staff for projects;

- The medical center agrees to pay the university the equivalent of $20 \%$ of the professor's salary.

\section{Mutual Goals}

Both agencies needed to decide on desired goals with the joint appointment. For the clinical agency, it was the benefit of having a doctoral-level nursing faculty spending dedicated time in the organization helping to establish, maintain, and grow a sound evidence-based practice. For the academic institution, the faculty had the opportunity to use research skills in a clinical 
setting. Both parties enjoyed the benefit of deeper collaboration between education and the practice environment.

\section{Shared resources}

The funding model to use for the joint appointments was also discussed. Models in the literature included the agency paying part of the salary per a contract (entrepreneurial model), a shared administrative structure to support the joint appointments (unification model) or individual faculty developing their own practice arrangements (private practice model) (4). The entrepreneurial model was chosen for our joint appointment agreements. In this model, the clinical facility paid the University for a certain number of faculty hours per week. This allowed the facility to have a doctoral-level researcher in the medical center without generating a new FTE. This model allowed the University some local generated funds to use to hire adjunct faculty to lighten the teaching load of the research faculty. In addition, it allowed the University to have a small amount of funds to support the research activities. The clinical agencies provide office space and computer support.

\section{Shared Responsibility and Shared Accountability}

The next phase of this venture was to nurture the new relationship and to ensure success. Three pre-scheduled meetings were planned for the first year to coordinate activity and ensure both administrators, staff, and the faculty were all pleased with the direction of the joint appointment. During these meetings focus was on the contract and on the direction agreed to during that first year. Issues that arose were sometimes as simple as whether the faculty had access to a computer and an office, to more complex issues such as who had access to the faculty-researcher. The details were worked out in these meetings as they arose. Both administrators remained 
committed to the arrangement. Administrators and staff from both agencies decided on projects.

Responsibilities were negotiated. Once the projects were completed, faculty and staff jointly developed abstracts for presentations.

\section{Successes Enjoyed}

During the first two years of the joint appointments, several projects were designed and completed. In addition, relationships were formed and the faculty embedded in the structures of the clinical organizations thereby legitimizing their practice. Lessons learned in the clinical settings were shared back with the faculty and students.

Projects in the first clinical agency included two research projects. The first project was a qualitative study that examined the readiness for evidence-based care in one clinical organization. This project was carried out primarily by the faculty, but lead to several discoveries that enabled the clinical agency to amend policy development and revision. The faculty benefited by getting an international presentation. In addition, a small study entitled the "PUP" study (pressure ulcer prevention study) was undertaken. This study was performed jointly with faculty and clinical staff. This project was designed to implement a new pressure ulcer policy in a controlled fashion using one unit as a control and one as an experimental unit. Clinical staff designed and carried out the study with guidance from the faculty. Even though no major differences were detected in this study, the significant finding was empowerment of the staff who participated in the study. 
This is a non-final version of an article published in final form in Journal of Nursing Administration, 36(11), 534-537. http://journals.lww.com/ jonajournal/pages/default.aspx

In the second agency, faculty and a clinical specialist worked with a unit manager and several staff on one unit. The process began with meetings where the staff was asked to identify concerns. After each meeting, the faculty and clinical specialist performed a literature review and wrote a synopsis of the literature for the next meeting. Eventually, a clinical topic of central line care was chosen. The staff then assumed responsibility for collecting data on infection rates, the procedure was amended, and care of central lines was changed. Educational sessions were held by the staff. Data were collected under the new procedure and compared with the pre-data.

While this study did indeed show an improvement in infection rates for central lines, the most amazing result was the empowerment of the staff. Clinical staff felt empowered by having a resource to answer questions based on evidence. The staff reported a greater sense of empowerment by being able to access resources to evaluate nursing practice and make changes for improvement. Faculty felt connected to practice and felt that their research skills were important and being utilized. In addition, faculty brought back practice issues to other faculty at the University.

For the next year, one facility is undertaking a major study of the first year experience of all nurses. This study was developed and guided by staff and the faculty with the joint appointment. The second facility has embraced the faculty as part of their focus on expanding evidence-based care. The faculty in the joint appointment is sought out by clinical staff. The faculty will be involved in developing presentations and measuring the effectiveness of programs in place in the facility. This facility sponsored an evidence-based practice symposium at the end of their second year with this partnership. The symposium included an internationally recognized nurse 
researcher as the keynote speaker, and included EBP project presentations by a panel of staff from the hospital. This symposium helped to cement evidence-based practice as a standard for nurses in the area.

\section{Lessons Learned}

Two years into these relationships, those involved report that goals on both sides have been reached, even surpassed in some instances. Though the joint appointments have worked well, there have been lessons learned:

1. Establish a contract in the beginning. A contract helps to maintain the joint appointments as business relationships. In addition, a contract allows both parties to list agreements and goals. As the appointment evolves, revisiting the contract reminds both parties of the initial agreements and changes can be made.

2. Meet frequently to ensure all parties are getting their needs met. As the faculty and staff work together, opportunities will arise that were not addressed initially. Frequent meetings allow administrators, faculty, and staff to review the opportunities available and ensure they are mutually beneficial.

3. Don't be too focused on any one project. If all parties involved allow relationships to grow between faculty and staff, projects will arise that may never would have been imagined! These projects are developed and designed by the staff, which contributes to empowerment.

4. Monitor the work faculty is doing and let others know about the projects. In the beginning, projects conducted may not be true "research.” However, faculty members are working to change culture by helping nurses to change the way they think about their 
practice. In addition, faculty is helping others within the University stay current with the practice issues. Even though faculty projects might not result in statistically significant findings, it is important to measure and report on the work conducted.

\section{The Future}

The joint research appointments are growing and changing as the agencies evolve. The empowerment of the staff and the excitement of the faculty involved at the grassroots level in helping nurses embrace evidence-based practice is encouraging. The American Organization of Nurse Executives have developed a nurse executive competency related to building partnerships and we are seeing more research related to the need for deeper and more meaningful partnerships between service and education $(5,6)$. Indeed, the deepened partnership between the department chair of the university and the vice presidents at the agencies was a side benefit not realized in the beginning. We hope to explore an expanded agenda for the future, including potential collaboration between multiple hospitals in the area and the university.

\section{Acknowledgment}

The authors thank Erin Kindberg for her assistance with final formatting and proof reading. 


\section{References}

1. University of Minnesota: Evidence-Based Nursing May 26, 2001. Available at http://evidence.ahc.umn.edu/ebn.htm. Accessed January 9, 2006.

2. Simpson R, Evidence-based nursing offers certainty in the uncertain world of healthcare. Nursing Management. 2004; 35(10):10-12.

3. Friend M, Cook L, Interactions: Collaboration skills for school professionals (2nd ed.). White Plains, NY: Longman; 1996.

4. Saxe J, et.al., What is faculty practice? Nursing Outlook. 2004; 52 (4):166-173.

5. AONE Nurse Executive Competencies. Nurse Leader. 2005:P52.

6. Woods T, Crain J, Enhancing collaboration with academic partners. Journal of Nursing Administration. 2005; 35(12):519-521. 